\title{
ESTUDOS SOROLÓGICOS PARA PESQUISA DE ANTICORPOS DE ARBOVIRUS EM POPULAÇÃO HUMANA DA REGIÃO DO VALE DO RIBEIRA. II - INQUÉRITO EM PACIENTES DO HOSPITAL REGIONAL DE PARIQUERA-AÇÚ, 1980 *
}

Lygia Busch Iversson **

Amélia P.A. Travassos da Rosa $* *$

Jorge Travassos da Rosa ***

\begin{abstract}
IVERSSON, L. B. et al. Estudos sorológicos para pesquisa de anticorpos de arbovírus em população humana da região do vale do Ribeira. II - Inquérito em pacientes do Hospital Regional de Paquera-Açú, 1980. Kev. Saúde públ., S. Paulo. $15: 587-602,1981$.
\end{abstract}

RESUMO: Foi realizado inquérito sorológico para pesquisa de anticorpos inibidores de hemaglutinaçãc de arbovírus em 516 moradores das zona.s urbana e rural da região do Vale do Ribeira, Brasil, área extensamente coberta de florestas onde ocorreu recentemente uma epidemia de encefalite atribuida ao Flavivirus Rocio. Verificou-se que $24,2 \%$ destas pessoas tinham anticorpos IH para um ou mais arbovírus $(11,2 \%$ para Alphavirus; $13,2 \%$ para Flavivirus; $4,6 \%$ para o Bunyavirus Caraparu e $0,8 \%$ para outros arbovírus). Alguns dos investigados, sem antecedente de vacinação contra febre amarela, apresentaram anticorpos neutralizantes para o virus da encefalite equina do Leste, St. Louis e da febre amarela, os dois últimos ainda não isolados na região. A análise das características dos indivíduos com sorologia positiva sugeria que a transmissão de arboviroses não era fato recente e estava se fazendo em pelo menos 9 municipios da área, não só no ambiente silvestre como fora do mesmo. Os indivíduos de sexo masculino e entre estes os que trabalham em pesca, em geral no periodo vespertino e noturno, apresentaram maior risco à infecções arbovíricas.

UNITERMOS: Hemaglutinação, anticorpos inibidores. Arboviroses. Inquéritos sorológicos.

\section{INTRODUÇÃO}

A região do Vale do Ribeira, situada no extremo sul do Estado de São Paulo, sudeste do Brasil, por suas feições climáticas, topográficas, hidrográficas, fitogeográficas e faunisticas apresenta condições favoráveis, tal como a Amazônia, para a existência e sobrevivência de arbovírus. A atenção para a pesquisa desses agentes etiológicos só foi despertada, no entanto, a partir de 1975 quando na região eclodiu uma epidemia de

* Realizado com auxílio financeiro parcial da Findação de Amparo à Pesquisa do Estado de São Paulo (FAPESP), Processo 04 biológicas 79/1495.

** Do Departamento de Epidemiologia da Faculdade de Saúde Pública da USP - Ar. Dr. Arnaldo, 715 - 01255 - São Paulo, SP - Brasil, e da Secretaria de Estado da Saúde de São Paulo - Ar. Dr. Arnaldo, 451 - 01246 - São Paulo, SP - Brasil.

*** Do Instituto Evandro Chagas, Fundação Serviços de Saúde Pública - Av. Almirante Barros, 492 - 66000 - Belém, PA - Brasil. 
IVERSSON, L. B. et al. Estudos sorológicos para pesquisa de anticorpos de arborírus em população humana da região do Vale do Ribeira. II - Inquérito em pacientes do Hospital Regional de Paquera-Açú, 1980. Rev. Saúde públ., S. Pa ulo, 15:587-602, 1981.

encefalite com caracteristicas de uma arbovirose (Tiriba $25.20,1975,1976$; Lopes ${ }^{1.5}$ 1978; Iversson 12.13 1977, 1980).

O Flaviviras Rocio, novo membro da familia Togaviridae, foi isolado de tecido cerebral de doentes falecidos (Lopes 151978 , Lopes e col.16 1978). No período de 1975 a 1978 extenso material (mosquitos, animais sentinela, sangue humano e de outros vertebrados) foi coletado na área epidêmica pelo Instituto Adolfo Lutz, São Paulo, tendo sido isolados desse material 47 arbovírus identificados como: encefalite equina do Leste, duas novas cepas de arbovirus antigenicamente relacionadas com o vírus da encefalomielite equina venezuelana, Rocio, Cananéia, Itimirim, Bertioga, Guaratuba, Caraparu, Borconha, Turlock, Tacaiuma, Cotia e Enseada (Lopes e col. ${ }^{\top}$ 1978; Calisher e col.3 1980).

Dois estudos sorológıcos efetuara-se em população humana residente na região. O primeiro, em 150 pessoas aparentemente sadias, revelou a presença de anticorpos inibidores de hemaglutinação para inúmeros arbovirus, notadamente o Bunyavirus, Caraparu em $40 \%$ dos soros e um ou mais Flavivirus (Rocio, St. Louis, Ilhéus, Bussuquara e da febre amarela) em $26 \%$ dos soros (Lopes e col. ${ }^{17}, 1978$ ). O segundo, um seguimento sorológico realizado de julho de 1977 a julho de 1978 em um grupo de homens que residiam em acampamentos no ambiente silvestre de 3 municípios da área, evidenciou conversão sorológica para um Flavivirus que não o Rocio em 2 moradores de um acampamento situado no municipio de Cananéia. Essa pesquisa mostrou que uma proporção de $20,5 \%$ dos investigados apresentava anticorpos inibidores de hemaglutinação para Alphavirus, $14,5 \%$ para 0 Bunyavirus Caraparu e $13,2 \%$ para Flavivirus (Iversson e col.14, 1980). A diferença significante entre a proporção de pessoas com anticorpos para Flavivirus nos dois inquéritos mencionados levou à hipótese que junto a núcleos urbanos e rurais houresse condições mais propícias à transmis- são de encefalite por Flavivirus do que no ambiente silvestre. Além disso, testes de soroneutralização positivos para vírus Ilhéus e St. Louis, responsáveis por quadros de encefalite humana, sugeria que aqueles pudessem também estar em atividade na área (lversson e col. ${ }^{14}$, 1980).

Tendo em vista a limitada disponibilidade de dados sobre a atividade de arbovirus na população humana residente no local, programaram-se outros inquéritos sorológicos. O primeiro deles, realizado junto à clientela do Hospital Regional de Pariquera-Açú para onde convergem doentes de toda a região, será descrito no presente trabalho.

\section{Caracteristicas da Area}

A regiāo estudada situa-se na parte sudeste do país e ocupa um território de 15.987 $\mathrm{km}$ 2, abrangendo 16 municípios, limitado a leste e sudeste pelo Oceano Atlântco e ao norte e noroeste pela cadeia montanhosa da Serra do Mar (Fig. 1). As escarpas desta serra nos extremos norte e sul aproximam-se do litoral, mas na parte central recuam para o interior possibilitando a existência de extensa planicie costeira de aproximadamente $2.400 \mathrm{~km}^{2}$, com altitudes sempre inferiores à cota de $100 \mathrm{~m}$, onde se expande o Rio Ribeira de Iguape e afluentes. A área apresenta-se extensivamente coberta de florestas $\left(8.350 \mathrm{~km}^{2}, 58 \%\right.$ do território) apesar dos constantes desmatamentos que vêm se processando de forma mais intensa nos últimos anos (Camargo e col. 1972 , Secr. de Economia e Planejamento ${ }^{19.23}$ 1974).

A mata tropical, em niveis baixos, prolonga-se em geral até a proximidade dos núcleos urbanos e rurais (Fig. 2). A periferia das cidades apresenta características de zona rural o que torna dificil uma delimitação nítida entre o urbano e o rural.

Na planicie o clima é tropical úmido, sem estiagem, com temperatura média, no mês mais frio, superior a $18^{\circ} \mathrm{C}$ ou mesotérmico úmido, sem estiagem, com temperatura média superior a $22^{\circ} \mathrm{C}$ no mês mais quente. Nas regiōes pré-serrana e serrana é meso- 
IVERSSON, L. B. et al. Estudos sorológicos para pesquisa de anticorpos de arbovírus em população humana da região do Vale do Ribeira. II - Inquérito em pacientes do Hospital Regional de Paquera-Açú, 1980. Rev. Saúde públ., S. Paulo, 15:587-602, 1981.

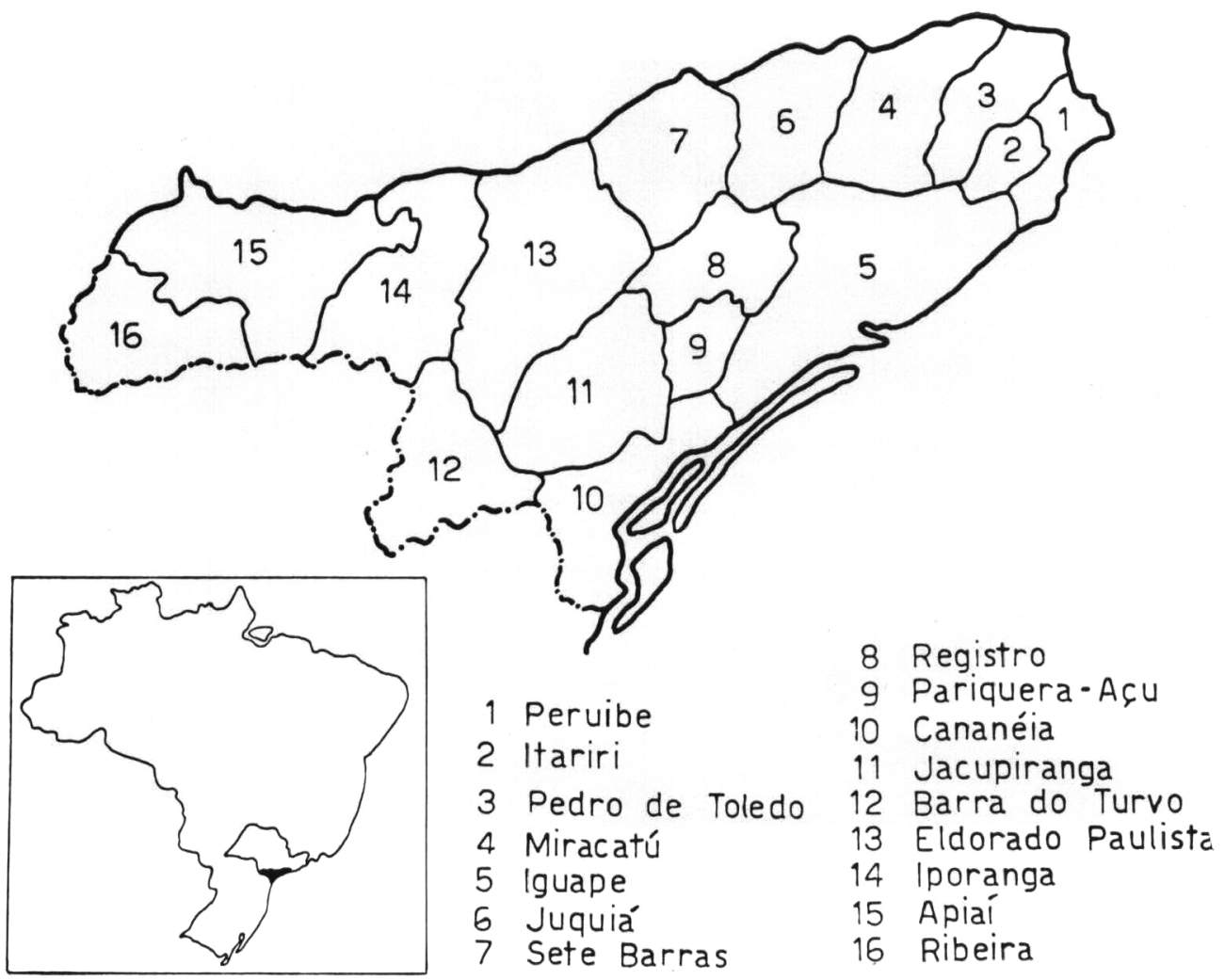

Fig. 1 - Localização e divisão administrativa da região do Vale do Ribeira.

térmico úmido, sem estiagem, com temperatura média inferior a $22^{\circ} \mathrm{C}$ no mês mais quente. A média anual de precipitação pluviométrica varia de $1.500 \mathrm{~mm}$ a $3.000 \mathrm{~mm}$. (Setzer 20, 1966). A presença de chuvas abundantes durante o ano todo e de um tipo de solo que impede a infiltração de água são fatores condicionantes da riqueza hidrográfica regional a qual desempenha função social relevante como fonte de alimento e meio de transporte do homem.

A população residente, 243.290 pessoas em 1980 (IBGE, 1980*), trabalha em atividades rurais predominantemente. Mais da metade desta populaçāo vive em peque- nos núcleos rurais, em geral em habitações de madeira e barro. As vias de comunicação para esses locais são precárias, não transitáveis na época de maior pluviosidade, mutivando seu isolamento e, consequientemente, dificultando 0 atendimento médico-sanitário dos residentes.

A fauna culicidiana regional é extremamente rica, apresentando variação de acordo com as caracteristicas das áreas pesquisadas (Forattini e col.1a.11, 1978).

Aspectos climáticos e fitogeográficos da região foram descritos de forma detalhada por Forattini e col.10 (1978).

* Fundação IBGE, Censo demográfico de 1980. Dados inéditos. 
IVERSSON. L. B. et al. Estudos sorológicos para pesquisa de anticorpos de arborírus em população humana da região do Vale ăo Ribeira. II - Inquérito em pacientes do Hospital Regional de Paquera-Açú. 1980. Reı. Saúde pübl,. S. Paulc. 15:587-602. 1981.

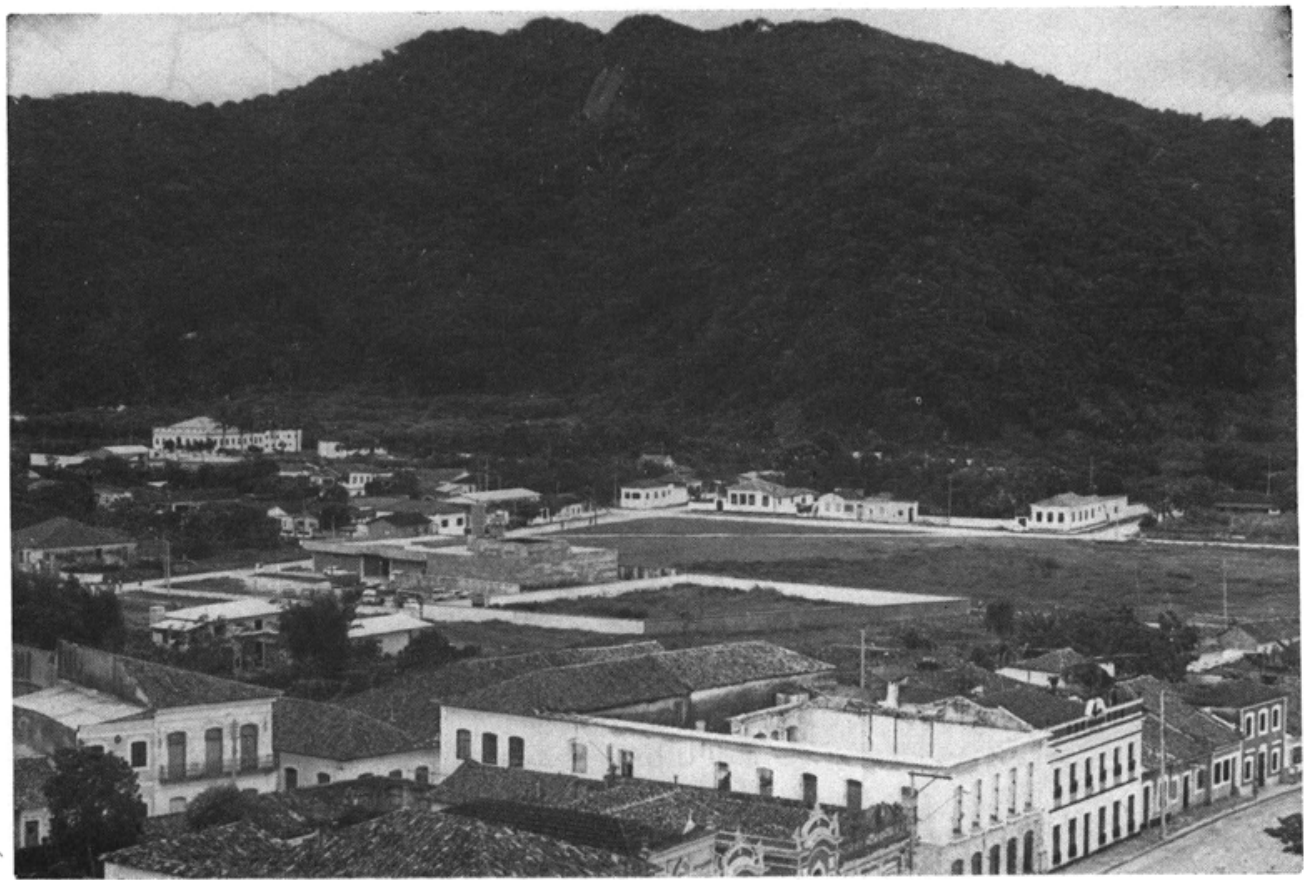

Fig. 2 - Aspecto da zona periffrica da cidade de Ig ape observando-se a proximidade das moradias com o ambiente florestal.

\section{Material E Métodos}

No período de fevereiro a agosto de 1980 foram coletados 516 soros de doentes que procuraram o maior hospital da área. Hospital Regional de Pariquera-Açu, por moléstias diversas ou para assistência ao parto. Não foram incluidos os pacientes que apresentaram suspeita clinica de meningite, encefalite ou meningoencefalite.

Não foi possivel, como desejável, obter uma amostra representativa quanto à idade, ao sexo, à procedência e à profissão da populaçāo residente nos 16 municipios da regiāo do Vale do Ribeira. Dada às características do Hospital, com um movimento maior de internaçōes de adultos e de parturientes, o levantamento sorológico abrangeu um grupo populacional de 9 a 82 anos de
Idade, onde predominaram pessoas acima de 15 anos $(97,1 \%$ ) principalmente na faixa etária dos 15 aos 44 anos $(71,1 \%)$, das quais $62,5 \%$ do sexo feminino. Uma proporção de $69,4 \%$ é natural da regiāo, nunca dela tendo saído. Entre os investigados, $72,8 \%$ mora ou já moro!l em zona rural.

$O$ inquérito incluiu pacientes que residem ou já residiram em 15 dos 16 municípios da área, principalmente em Pariquera-Açu $(20,1 \%$ dos pescuisados) Jacupiranga $(19,2 \%)$ Iguape (13,8\%) Registro (10 8\%) e Cananéia $(8,9 \%)$. Estes locais apresentaram altos coeficientes de morbidade por encefalite durante a epidemia de 1975-1977.

Em todas as pessoas pesquisadas investigou-se antecedente de encefalite, febre amarela e vacinação contra estas moléstias. Cumpre esclarecer que a vacina de febre amarela não é aplicada ña região desde 1953 
IVERSSON, L. B. et al. Estudos sorológicos para pesquísa de anticorpos de arbovírus em população humana da regiăo do Vale do Ribeira. II - Inquérito em pacientes do Hospital Reglonal de Paquera-Açú, 1980. Rev. Saúde públ., S. Paulo, 15:587-602, 1981.

(SUCAM*) e que a vacina contra encefalite por Rocio, produzida recentemente pelo Instituto Butantã, São Paulo, só foi utilizada em um estudo-piloto em funcionários de uma empresa particular situada no municipio de Jacupiranga. (Secretaria de Estado da Saúde de São Paulo)*.

O sangue foi coletado por punção venosa. Os soros foram conservados a- $20^{\circ} \mathrm{C}$ até a realização dos testes sorológicos.

A reação de inibição de hemaglutinação (IH) foi realizada para 18 antigenos de arbovirus isolados no Brasil: encefalite equina do Leste (EEL), encefalite equina do Oeste (EEO); Mayaro, Mucambo, febre

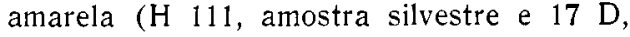
vacina) Bussuquara, Ilhéus, St. Louis, Rocio, Caraparu, Guaroa, Oropouche, Utinga, Tacaiuma, Icoaraci e duas possiveis novas amostras, AN 327600 (Flavivirus) e AR 314206 (Bunyavirus). Foi utilizada microtécnica descrita por Shope 21 (1963), os antígenos tendo sido preparados de cérebro de camundongo recém-nascido pela técnica da extração com sucrose-acetona ou de soro de camundongo ou hamster por extração com acetona; os soros foram tratados por acetona e absorvidos por hemácias de ganso.

Nos testes de neutralização empregou-se técnica de soro constante (diluição final 1: 8) com variação de 10 vezes na diluição do virus (Casals ${ }^{5}, 1967$ ). As misturas, incubadas a $37^{\circ} \mathrm{C}$ por uma hora, foram inoculadas intracerebralmente em camundongos albinos, tendo sido considerados positivos os soros com um logarítmo do índice de neutralização $\geqslant 1,7$.

Nas Tabelas 5, 6, 7 e 9 os resultados dos testes IH referem-se aos gêneros a que pertencem os diversos arbovírus (Berge ${ }^{1}$, 1975): Alphavirus (Grupo A) Flavivirus (Grupo B) e Bunyavirus (Grupo C). Na categoria "outros arbovirus" foram incluídos outros membros do gênero Bunyavirus
(Grupos Bunyanwera, Anopheles A e Simbu), gênero Phlebovirus (Grupo Phlebotomus) e arbovirus não grupados, cujos anticorpos aparecem com baixa freqüência. Esta conduta foi adotada tendo em vista a reatividade sorológica cruzada entre os componentes de um grupo dificultando a análise individualizada dos resultados.

\section{RESULTADOS}

\section{Antecedente de vacinação}

Quatro pessoas que referiram vacinação anterior contra febre amarela e uma contra encefalite por Rocio não apresentaram anticorpos para os arbovírus testados.

\section{Antecedente de febre amarela ou encefalite}

Nenhum dos investigados relatou antecedente de febre amarela.

Duas pessoas mencionaram antecedente de encefalite diagnosticada em hospital da região. Não há informação de sorologia para arbovirus destes pacientes na época da moléstia. Um deles, operário residente há 15 anos no bairro do Rocio (Iguape) apresentou, no presente inquérito, reação monotípica para vírus Rocio (título 80). O outro, lavradora de 57 anos, sempre residente em zona rural do municipio de Pariquera-Açu, mostrou, no teste de $\mathrm{IH}$, reação monotípica para vírus da encefalite equina do Leste (título 20); o teste de soroneutralização em camundongo para este vírus foi positivo (logaritmo do índice de neutralização $\geqslant 2,8$ ).

\section{Testes sorológicos}

Em 24,2\% dos soros das 516 pessoas estavam presentes anticorpos IH para um ou mais arbovírus testados. Anticorpos dos virus St. Louis, Mucambo, EEL, Ilhéus e Caraparu foram os mais frequientes (Tabela

* Comunicação verbal. 
IVERSSON, I. B. et al. Estudos sorológicos para pesquisa de anticorpos de arbovírus em população humana da região do Vale do Ribeira. II - Inquérito em pacientes do Hospital Regional de Paquera-Açú, 1980. Rev. Saúde pübl., S. Paulo, 15:587-602, 1981.

\section{TA B E L A 1}

Resultados dos testes de inibição de hemaglutinação para arbovírus realizados em soros coletados de pacientes do Hospital Regional de Pariquera-Açú, 1980.

\begin{tabular}{|c|c|}
\hline \multirow{2}{*}{ Antigeno } & Soros positivos \\
\hline & Soros testados \\
\hline $\mathrm{EE} \mathrm{L*}$ & $29 / 516$ \\
\hline $\mathrm{EEO}$ & $11 / 516$ \\
\hline Mayaro & $5 / 516$ \\
\hline Mucambo & $34 / 516$ \\
\hline $\begin{array}{l}\text { Febre Amarela } \\
\quad \text { (amostra silvestre } \mathrm{H} 111 \text { ) }\end{array}$ & $8 / 516$ \\
\hline Febre amarela (vacina $17 \mathrm{D}$ ) & $14 / 516$ \\
\hline Bussuquara & $3 / 516$ \\
\hline Ilhéus & $27 / 516$ \\
\hline St. Louis & $35 / 516$ \\
\hline Rocio & $22 / 516$ \\
\hline An $327600 * *$ & $15 / 516$ \\
\hline Caraparu & $24 / 516$ \\
\hline Guaroa & $3 / 516$ \\
\hline Oropouche & $2 / 516$ \\
\hline Utinga & $3 / 516$ \\
\hline Tocaiuma & $2 / 516$ \\
\hline AN $314206 * * *$ & $1 / 516$ \\
\hline Icoaraci & $0 / 516$ \\
\hline
\end{tabular}

* Encefalite equina do Leste

* Encefalite equina do Oeste

*** Possíveis novos tipos

1). É interessante observar que o número de soros com reação monotípica para os virus Mucambo, EEL e St. Louis foi maior do que para Rocio, o único arbovirus até o momento responsabilizado por moléstia humana na área (Tabela 2).

Em soros reagentes no teste $\mathrm{IH}$ para o virus da febre amarela (amostras silvestre e vacina 17D), St. Louis e EEL foram executados testes de neutralização em camundongo, tendo-se confirmado os resultados positivos em cerca de $80 \%$ dos soros testa- dos para St. Louis e EEL (Tabela 3). Em relação ao vírus da febre amarela, 8 pessoas entre as 14 pesquisadas apresentaram resultado positivo no teste de neutralização. Uma delas, com reação monotípica no teste de $\mathrm{IH}$, é um rapaz de 13 anos de idade, lavrador, nascido no municipio de Juquiá onde residiu até há 10 meses atrás quando mudou-se para zona rural do município de Eldorado Paulista. Os dois locais estão situados na região do Vale do Ribeira. Esse paciente, internado no Hospital Regional em consequiência de sarampo e broncopneumonia, nunca saiu da área e certamente não foi vacinado contra a febre amarela. Os outros 7 indivíduos com neutralização positiva para febre amarela também negaram vacinação anterior. São, no entanto, pessoas de mais de 30 anos de idade, duas delas tendo residido em outros locais, fatos estes que tornam possivel ter ocorrido essa vacinação sem que o doente dela se recorde.

Observando-se algumas características de interesse dos investigados que apresentaram sorologia positiva verifica-se o seguinte:

Naturalidade: não existe diferença signiticante $\left(x_{2}=0,58<3,841\right.$ para $\left.\alpha=5 \%\right)$ entre a proporção de pessoas com anticorpos IH para arbovírus naturais da região e as migrantes (Tabela 4). Cumpre assinalar que $2 / 3$ destes migrantes com sorologia positiva vivem na área há 5 ou mais anos e nenhum há menos de 9 meses.

Entre os naturais com sorologia positiva há 49 indivíduos que sempre residiram no municipio de nascimento (Tabela 5) o que leva a supor que pelo menos em 9 municipios, situados na planície e nas regióes pré-serrana e serrana, se verifica a circulação de arbovírus na população humana.

Idade - Há, em geral, um crescente aumento com a idade da proporção de soros com anticorpos para os arbovírus testados, fato esse bem evidente em relação a Flavivirus (Tabela 6). Esta distribuição etária crescente não é observada nas 12 pessoas que apresentaram ou reação monotípica para 
IVERSSON, I. B. et al. Estudos sorológicos para pesquisa de anticorpos de arbovirus em população humana da região do Vale do Ribeira. II - Inquérito em pacientes do Hospital Regional de Paquera-Açú, 1980. Rev. Saúde públ., S. Paulo, 15:587-602, 1981.

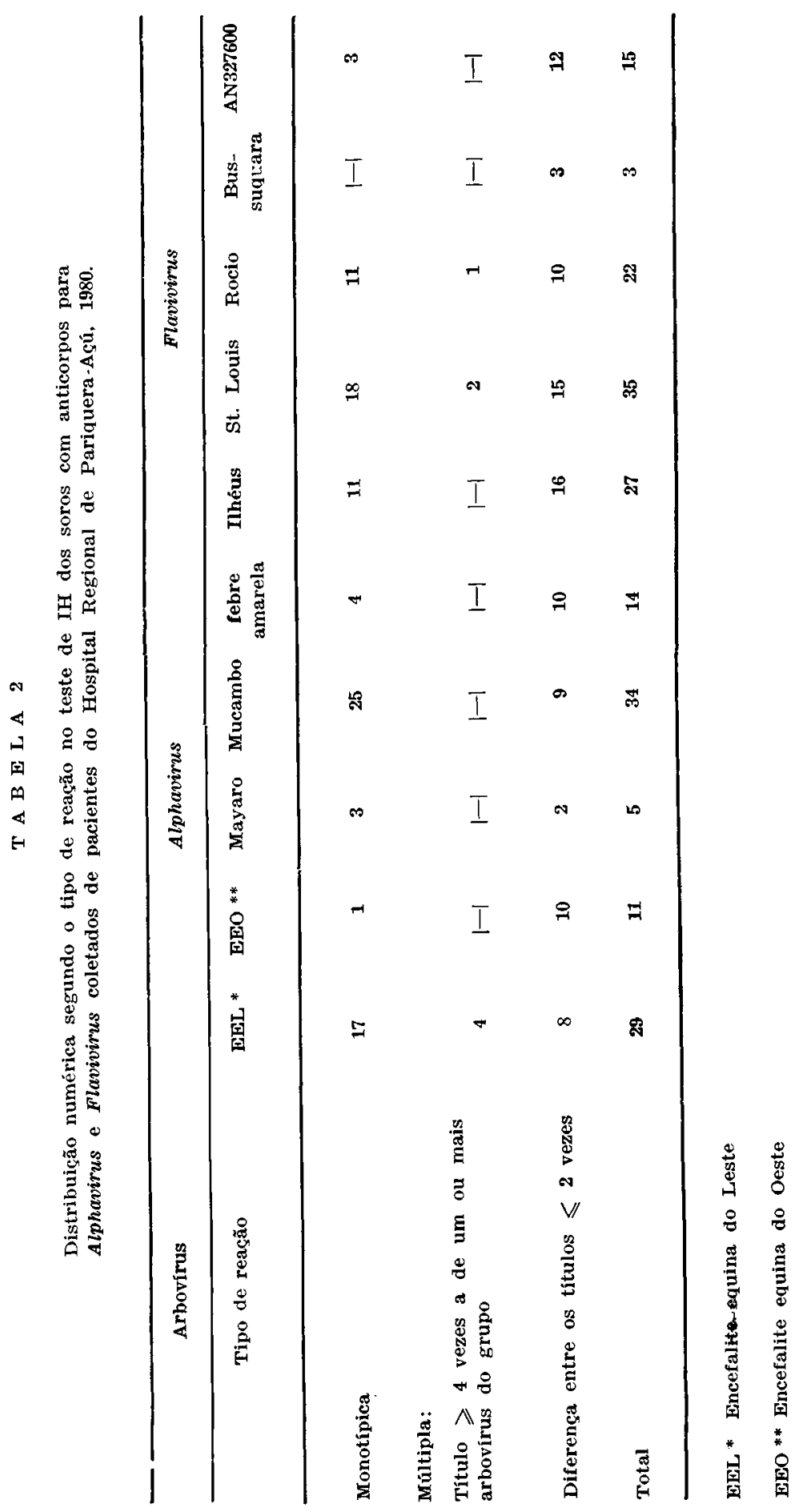


IVERSSON, L. B. et al. Estudos sorológicos para pesquisa de anticorpos de arbovírus em população humana da região do Vale do Ribeira. II - Inquérito em pacientes do Hospital Regional de Paquera-Açú, 1980. Rev. Saúde públ., S. Paulo, 15:587-602, 1981.

\section{T A B E L A 3}

Comparação entre a presença de anticorpos inibidores de hemaglutinação (IH) e neutralizantes (N) dos vírus da febre amarela. St. Louis e encefalite equina do Leste (EEL) em soros coletados no Hospital Regional de Pariquera-Açú. 1980.

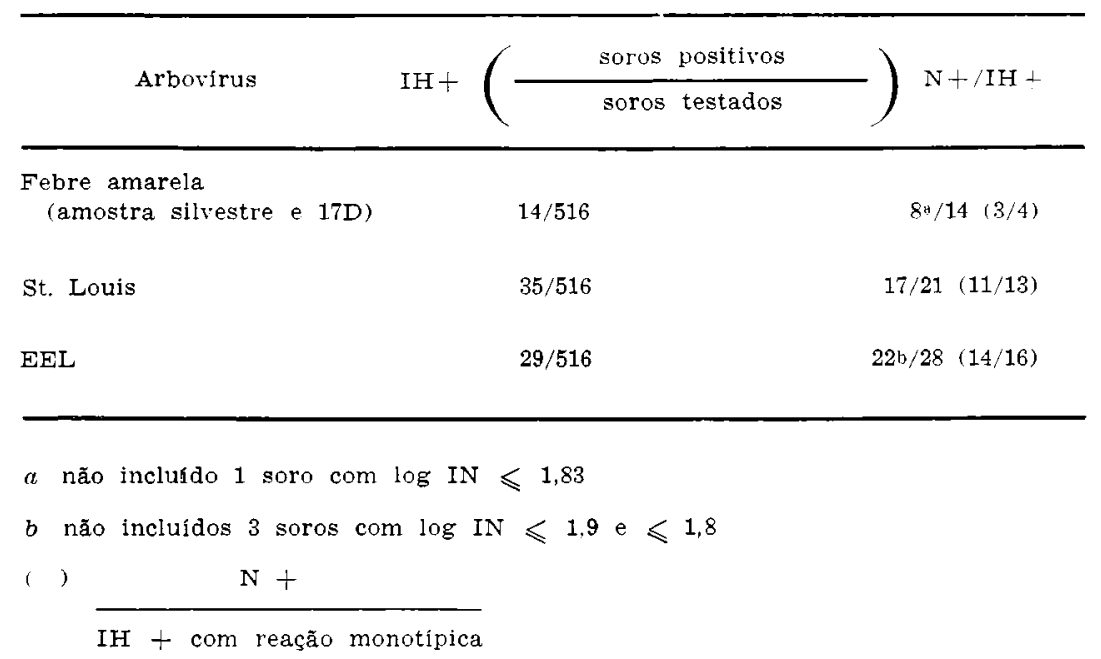

T A B E L A 4

Distribuição numérica e percentual segundo naturalidade e resultados dos testes de inibição de hemaglutinação para arbovírus de pacientes do Hospital Regional de Pariquera-Açu, 1980.

\begin{tabular}{|c|c|c|c|c|c|c|}
\hline \multirow{2}{*}{ Naturalidade } & \multicolumn{2}{|c|}{ Soros Positivos } & \multicolumn{2}{|c|}{ Soros Negativos } & \multicolumn{2}{|c|}{ Total } \\
\hline & $\mathrm{N}$ & $\%$ & No & $\%$ & $N_{9}$ & $\%$ \\
\hline $\begin{array}{l}\text { Município da Região do Vale do } \\
\text { Ribeira }\end{array}$ & 88 & 23.3 & 289 & 76,7 & 377 & 100,0 \\
\hline $\begin{array}{l}\text { Outros Municípios do Estado de } \\
\text { São Paulo ou outros Estados } \\
\text { do Brasil }\end{array}$ & 37 & 26,6 & 102 & 73,4 & 139 & 100,0 \\
\hline Total & 125 & 24,2 & 391 & 75,8 & 516 & 100,0 \\
\hline
\end{tabular}


TVERSSON. L. B. et al. Fistudos sorológicos para pesquisa de anticorpos de arbovírus em população humana da regiāo do Vale do Ribeira. II - Inquérito em pacientes do Hospital Regional de Paquera-Açú, 1980. Rev. Saúde pübl., S. Paulo, 15:587-602, 1981.

\section{T A B E L A 5}

Prssença de anticorpos IH de arbovírus em pacientes do Hospital Regional de Pariquera-Açu, nat.rais da região do Vale do Ribeira que sempre viveram no municipio de nascimento.

\begin{tabular}{|c|c|c|c|c|}
\hline Municipio $\begin{array}{c}\text { Anticorpos } \\
\text { de nascimento }\end{array}$ & Alphavirus & Flavivirus & $\begin{array}{c}\text { Caraparu } \\
\text { (Bunyavirus) }\end{array}$ & $\begin{array}{l}\text { Total das } \\
\text { pessoas * }\end{array}$ \\
\hline Barra do Turvo & $1-$ & 1 & $1-1$ & 1 \\
\hline Cananéia & 3 & 5 & 1 & 7 \\
\hline Eldorado Paulista & 2 & 2 & $1-1$ & 4 \\
\hline Ig ape & 7 & 8 & 2 & 14 \\
\hline Jacupiranga & 1 & 5 & 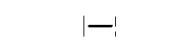 & 5 \\
\hline Miracatú & 1 & 1 & $1-1$ & 2 \\
\hline Pariquera-Açu & 10 & 5 & 3 & 12 \\
\hline Registro & - & 1 & 1 & 2 \\
\hline Iporanga & -1 & 2 & $1-1$ & 2 \\
\hline Total & 24 & 30 & 7 & 49 \\
\hline
\end{tabular}

- Algumas das pessoas apresentaram anticorpos para arbovírus pertencentes a mais de um grupo.

Rocio ou reação múltipla com título quatro vezes maior para este vírus em relação aos demais do grupo. No entanto, as pessoas com reação monotípica ou reação múltipla com título quatro vezes maior para o virus St. Louis mostraram essa distribuição etária crescente, havendo mesmo uma concentração de soros positivos no grupo etário acima de 54 anos de idade $(10,2 \%$ do total de investigados nesse grupo etário), concentração esta semelhante a que ocorre quando grupos populacionais de outros paises têm sido infectados por esse agente. Os anticorpos do vírus Caraparu são encontrados com maior freqüência na faixa etária dos 25 aos 44 anos.

Sexo - No resultado global a porcentagem de homens com anticorpos IH para arbovirus é significantemente maior do que a das mulheres $(\times 2=9,09>3,841$ para $\alpha=5 \%$ ) (Tabela 7). Nota-se também que em relação ao vírus Caraparu é semelhante a proporção dos atingidos nos 2 sexos.

Ocupação habitual - Chama a atenção a alta proporção de pescadores com sorologia positiva (Tabela 8 ).

Local de residência - Comparando-se os dados deste inquérito com o realizado anteriormente em um grupo de homens residente em ambiente silvestre (Iversson e col. ${ }^{17}, 1980$ ) verifica-se que nesse último grupo existe maior proporção de individuos com anticorpos IH para os diversos arbovirus testados com exceção dos Flavivirus quando ela é semelhante a do presente inquérito. Ao analisar na Tabela 9 a prevalência de anticorpos nos dois grupos populacionais, segundo a ocupação habitual, observam-se dois fatos de interesse: 1 não há diferença significante $\times 2=0,81<$ 

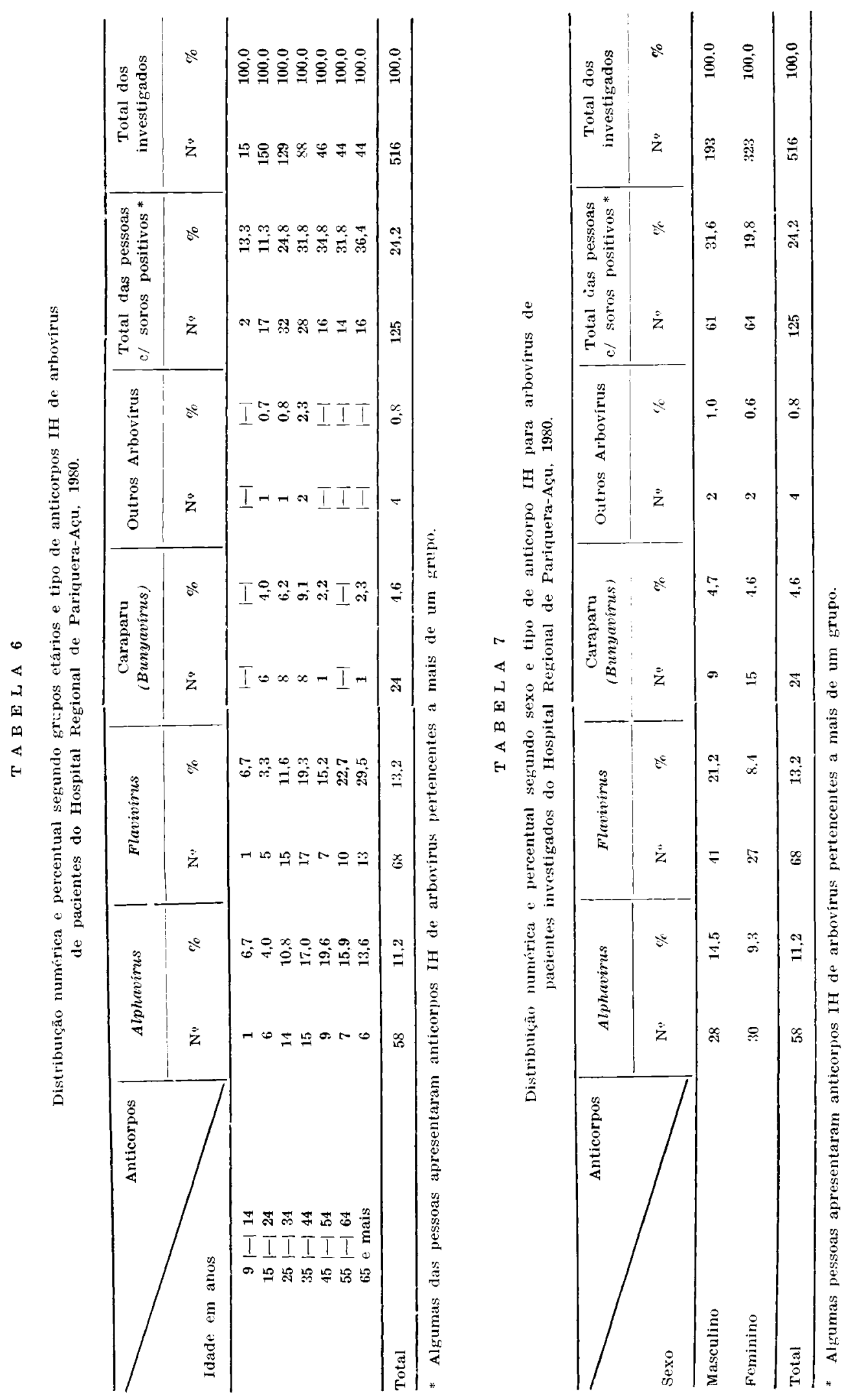
IVERSSON, L. B. et al. Estudos sorológicos para pesquisa de anticorpos de arbovírus em população humana da região do Vale do Ribeira. II - Inquérito em pacientes do Hospital Regional de Paquera-Açú, 1980. Rev. Saúde públ., S. Paulo, 15:587-602, 1981.

T A B E L A 8

Distribuição numérica e percentual segundo ocupação habitual e resiltados dos testes de inibição de hemaglutinação para arbovirus de pacientes do Hospital Regional de Pariquera-Açu, 1980.

\begin{tabular}{|c|c|c|c|c|c|c|}
\hline \multirow{2}{*}{$\begin{array}{c}\text { Ocupação } \\
\text { habitual }\end{array}$} & \multicolumn{2}{|c|}{ Soros positivos } & \multicolumn{2}{|c|}{ Soros negativos } & \multicolumn{2}{|c|}{ Total } \\
\hline & No & $\%$ & No & $\%$ & No & $\%$ \\
\hline Pescator & 7 & 70,0 & 3 & 30,0 & 10 & 100,0 \\
\hline Lavrador & $48 *$ & 29,4 & 115 & 70,6 & 163 & 100,0 \\
\hline $\begin{array}{l}\text { Prendas } \\
\text { domésticas }\end{array}$ & $58 * *$ & 21,4 & 213 & 78,6 & 271 & 100,0 \\
\hline Operário & 1 & 14,3 & 6 & 85,7 & 7 & 100,0 \\
\hline $\begin{array}{l}\text { Outras } \\
\text { profissões*** }\end{array}$ & 10 & 24,4 & 31 & 75,6 & 41 & 100,0 \\
\hline Estudante & $1-1$ & $1-1$ & 16 & 100,0 & 16 & 100,0 \\
\hline Menor & $1-1$ & $1-1$ & 5 & 100,0 & 5 & 100,0 \\
\hline Aposentado & 1 & 33,3 & 2 & 66,7 & 3 & 100,0 \\
\hline Total & 125 & 24,2 & 391 & 75,8 & 516 & 100,0 \\
\hline
\end{tabular}

* 6 lavradores também exercem atividades de pesca.

* 3 donas de casa também ajudam na lavoura.

*** Funcionário público, comerciante, pedreiro, pintor, eletricista, fotógrafo, motorista, cozinheira de restaurante, borracheiro, vigia.

3,841 para $\alpha=5 \%$ ) em relação a anticorpos para Alphavirus dos que trabalham e residem no ambiente silvestre e dos que residem em zona rural e urbana e trabalham em lavoura ou pesca. O mesmo não ocorre $\epsilon m$ relação aos que exercem atividades habituais no ambiente urbano ou domicilio. 2 - Não há diferença significante em relação a anticorpos de Flavivirus do grupo que trabalha e reside no ambiente silvestre e dos que vivem em ambiente urbano ou rural e trabalham na lavoura e pesca ( $X 2$ $=1,37<3,841$ para $\alpha=5 \%$ ) no domicilio $(\times 2=1,16<3,841$ para $\alpha=5 \%)$ e em outras atividades $(\times 2=0,74<3,841$ para $\alpha=5 \%$ ). Resumindo, todas essas pessoas apresentaram um risco semelhante de adquirir infecções por Flavivirus.

\section{COMENTARIOS}

Um estudo desta natureza não permite identificar especificamente os arbovirus em atividade na área estudada o que só é possivel com o isolamento dos mesmos nos seus hospedeiros naturais, em vetores ou em animais sentinela. A já amplamente demonstrada reatividade sorológica cruzada entre arbovirus de um mesmo grupo (Casals ${ }^{6}$, 1944, Theiler e Casals ${ }^{24}, 1958$, Casals 7 , 1963) soma-se ao fato da população do Vale do Ribeira residir ou trabalhar 
IVERSSON. L. B. et al. Estudos sorológicos para pesquisa de anticorpos de arborírus em populaçāo humana da região do Vale do Ribeira. II - Inquérito em pacientes do Hospital Regional de Paquera-Açú, 1980. Rev. Saúde públ., S. Paulo, 15:587-602, 1981.

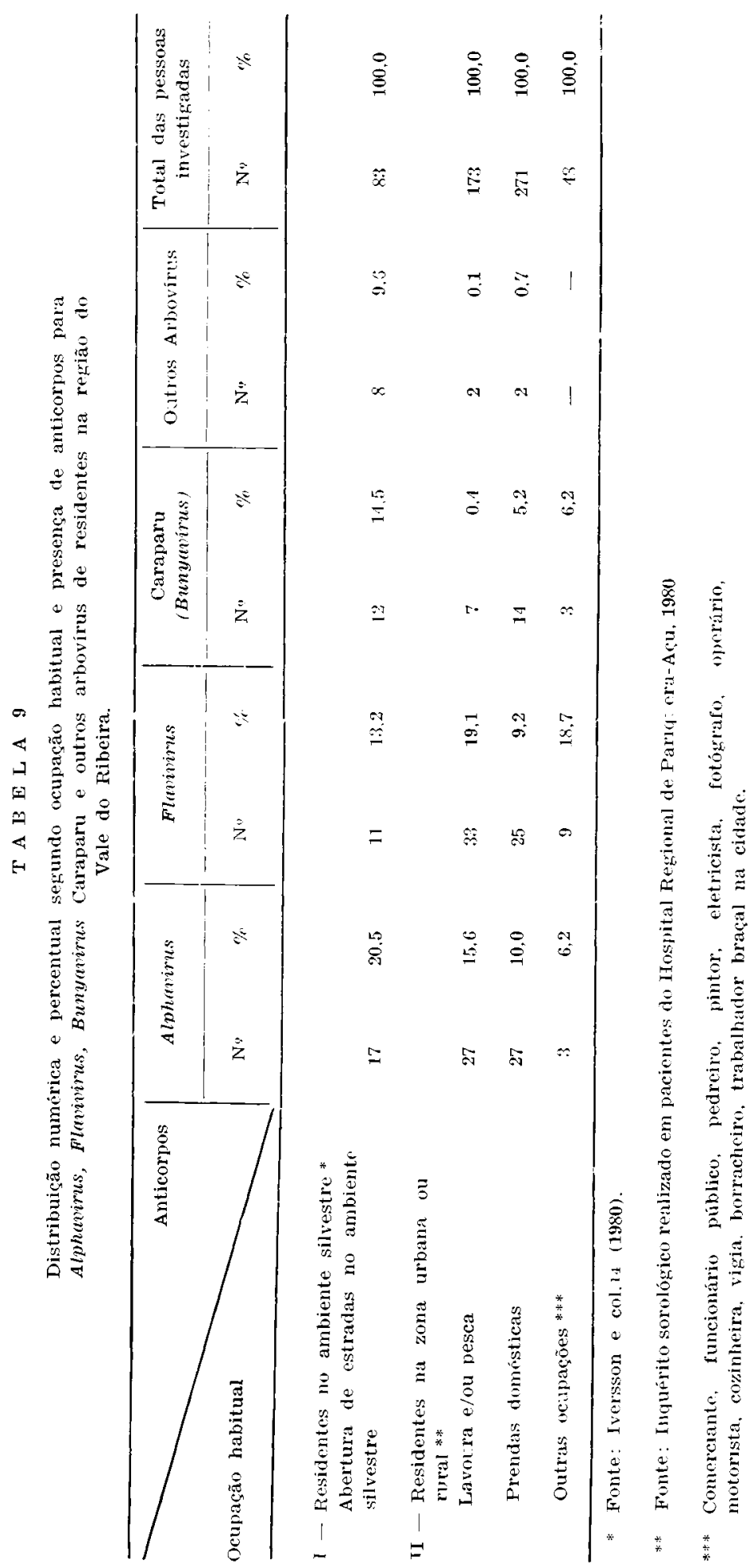


IVERSSON, L. B. et al. Estudos sorológicos para pesquisa de anticorpos de arbovírus em população humana da região do Vale do Ribeira. II - Inquérito em pacientes do Hospital Regional de Paquera-Açú, 1980. Rev. Saúde públ., S. Paujo, 15:587-602, 1981.

em estreito contacto com o ambiente silvestre, estando sujeita a infecções repetidas, por arbovirus, inclusive pelos antigenicamente relacionados. Desta forma, poder-se-ia prever nos resultados positivos a presença de reações secundárias caracterizadas por altos títulos de anticorpos heterólogos, o que dificulta a interpretação dos dados.

Outro aspecto a ser considerado é que foram testados antígenos de 17 arbovirus já isolados no Brasil. Outros arbovirus, isolados ou não no pais ou mesmo desconhecidos, poden estar em atividade na área circulando na população humana ou fora dela em ciclos enzoóticos.

Tendo presente estas limitaçòes, ainda nos foi possivel obter informações de interesse tais como o fato de que $1 / 4$ da população investigada já teve pelo menos uma infecção clinica ou sub-clínica por arbovirus. Não há, no entanto, nos registros de morbidade e mortalidade locais referência a arboviroses, con exceção da encefalite por Rocio a partir de 1975. É provável que frequientemente não tenham sido diagnosticadas, seja pelo isolamento geográfico de parte da populaçāo, seja pelo despreparo da estrutura laboratorial regional para realizar exames que permitam o diagnóstico etiológico das arboviroses, seja pela não preocupação dos clinicos em associar esta etiologia a quadros clínicos não definidos. Mesmo algumas das encefalites atribuidas ao vírus Rocio podem ter sido causadas pelos virus St. Louis, llhéus, da encefalite equina do Leste ou por novo arbovirus antigenicamente relacionado com o vírus de encefalomielite equina venezuelana, os dois últimos já isolados na região de pools de Culex (Melanoconion) sp e de um quiróptero (Calisher e col.3, 1980). A presença exclusiva de anticorpos neutralizantes de EEL em uma paciente investigada que refere antecedente de encefalite, obviamente, não autoriza um diagnóstico pregresso desta arbovirose, mas sugere a possibilidade.

Outra observação a ser analisada é a existência de anticorpos neutralizantes de febre amarela em um rapaz de 13 anos de idade, seguramente não vacinado contra a moléstia e que nunca se ausentou da região. Este fato isolado, embora constitua um indicio, não permite concluir sobre a presença e circulação do vírus da febre amarela na área, uma vez que existe a eventualidade da reação ter sido determinada por um Flavivirus que apresente afinidade antigênica com o da febre amarela e que não tenha reatividade cruzada com os outros Flavivirus testados. O prosseguimento dessas pesquisas em grupos populacionais não vacinados contra a moléstia e a execução de estudos que objetivem o isolamento do vírus em reservatórios naturais ou em vetores permitirão esclarecer o assunto de relevante significado. Não se dispõe de dados recentes sobre a população de macacos da área, mas informações de moradores que frequientam o ambiente silvestre relatam a presença habitual desses primatas en alguns dos municípios locais.

Quanto ao virus da encefalite de St. Louis, de transmissão humana em geral domiciliar, já foi isolado no período de 1967 a 1969 por Lopes e col.18 (1979) em duas localidades do Estado de São Paulo (Casa Grande e Rio Guaratuba), próximas à região do Vale do Ribeira, com caracteristicas climáticas, topográficas e fitogeográficas semelhantes a essa.

Esses achados mostram que há necessidade de maior ênfase regional à vigilância epidemiológica das arboviroses, especialmente da febre amarela por meio de medidas como a execução, a nivel regional, dos exames de laboratório que permitam o diagnóstico etiológico e a execução rotineira de exames anatomopatológicos de material hepático em óbitos determinados por moléstia febril não perfeitamente esclarecida.

Outra informaçāo de interesse é a relativa à distribuição etária dos investiợados com so:ologia positiva para Alphavi us e Flavivirıs, cuja proporção aumenta com a idade, evidenciando que o contacto da população humana com estes agentes se faz há um tempo longo. 
IVERSSON, L. B. et al. Estudos sorológicos para pesquisa de anticorpos de arbovirus em população humana da região do Vale do Ribeira. II - Inquérito em pacientes do Hospital Regional de Paquera-Açú, 1980. Rev. Saúde públ., S. Paulo, 15:587-602, 1981.

Merece um comentário o comportamento das pessoas pesquisadas em relação ao vírus Caraparu, isolado pela primeira vez no Pará, Brasil em 1956, pertencente ao gênero Bunyavirus, apresentando afinidade antigênica marcada nos testes de $\mathrm{IH}$ com o virus Apeu e menos evidente com o vírus Marituba e Murucutu, nos testes de neutralização com o vírus Apeu e Murucutu e nas provas de fixação de complemento com o virus Itaqui (Causey e col.), 1961; Casals e Whitman 8, 1961; Buckley e Shope 2, 1961; Shope e Causey 2:, 1962). Esses arbovírus do Grupo C, isolados no Pará, determinam no homem moléstia febril com prostração, mialgias ou artralgias. No presente inquérito uma proporção semelhante de homens e de mulheres, estas exclusivamente donas de casa, apresentaram anticorpos para Caraparu, evidenciando exposição similar a esse agente explicável no caso de transmissão domiciliar ou peridomiciliar.

A ocorrência de transmissão de Alphavirus e Flavivirus fora do ambiente silvestre também é sugerida pelos dados aqui analisados. O fato da população do Vale do Ribeira residir próximo a matas, onde se supõe a existência de focos naturais de arbovírus, não indica que para se infectar esta população necessite obrigatoriamente penetrar no interior das mesmas. Vetores silvestres podem estar levando a infecção ao homem ao frequientar o ambiente natural alterado, ou seja, campos de cultura, pastagens, peridomicilio ou o próprio domicílio. Esta possibilidade já foi anteriormente aventada em relação à transmissão da encefalite por Rocio em publicação referente a levantamentos entomológicos recentemente desenvolvidos na área (Forattini e col..1, 1978).

O último aspecto a ser assinalado é a alta proporção de pescadores com sorologia positiva para arbovírus. $O$ número dos investigados é baixo e merece ser ampliado em estudo posterior, uma vez que o fato tem significado epidemiológico, pois estes homens exercem seu trabalho em geral em horário vespertino e noturno, oposto a de outros profissionais. A maior transmissão das arboviroses poderia estar relacionada à maior densidade dos vetores neste horário. Cumpre assinalar que pessoas registradas como lavradores também executam atividade de pesca nas épocas de safra de pescado. E uma decorrência do baixo rendimento do trabalho agrícola e da proximidade das moradias da orla marítima e dos cursos de água.

\section{CONCLUSOES}

1. Em 24,2\% dos pesquisados estavam presentes anticorpos para um ou mais arbovirus.

2. A transmissão das arboviroses por Alphavirus, Flavivirus e Bunyavirus parece estar se fazendo tanto no ambiente silvestre com nas áreas naturais alteradas pela ação do homem. Em pelo menos 9 municípios da região está ocorrendo transmissão à população humana.

3. Há indicios sorológicos que sugerem a presença de arbovirus de grande importância epidemiológica, ainda não isolados no local, como o vírus St. Louis e o virus da febre amarela (ou de um agente com estreito relacionamento antigênico ao mesmo).

4. Há indicios sugestivos que outros arbovirus além do Rocio tenham sido responsáveis por casos de encefalite ocorridos na região.

5. Entre os pacientes investigados do Hospital Regional de Pariquera-Açu, os individuos do sexo masculino, particularmente os pescadores foram os que mostraram maior risco à infecção por arbovirus.

\section{AGRADECIMENTO}

Ao Dr. Leopoldo Bevilacqua, diretor do Hospital Regional de Pariquera-Açu e à sua equipe que nos franquearam o Hospital para esta pesquisa. Aos membros do CENTEP (Centro Brasileiro de Estudos Entomológicos em Epidemiologia) pela valiosa colaboração prestada. 
IVERSSON, L. B. et al. Estudos sorológicos para pesquisa de anticorpos de arbovírus em população humana da região do Vale do Ribeira. II - Inquérito em pacientes do Hospital Regional de Paquera-Açú, 1980. Rev. Saúde pübl., S. Paulo, 15:587-602. 1981.

IVERSSON, L. B. et al [A serological study for research of arbovirus antibodies in human population of the Ribeira Valley Region. II - A survey of patjents in the Pariquera-Açu Regional Hospital, 1980]. Rev. Saúde públ., S. Paulo, 15: $587-602,1981$.

ABSTRACT: A serological survey for hemagglutination-inhibition antibodies to arbovirus was carried out on 516 residents of the rural and urban zones of the Ribeira Valley, Brazil, a largely forested area where there recently occurred an encephalitis epidemic attributed to Flavivirus Rocio. It was discovered that $24.2 \%$ of the sample population presented HI antibodies $\mathbf{1 1 . 2 \%}$ against Alphavirus, $13.2 \%$ against Flavivirus, $4.6 \%$ against the Caraparu virus and $0.8 \%$ against other arboviruses). Neutralizing antibodies for Eastern equine encephalitis, St. Louis encephalitis and yellow fever virus were detected in some of the people, not vaccinated against yellow fever, who have always lived in the region. These last two viruses have never before been isolated in the area. The characteristics of people who presented antibodies suggest that the transmission of arboviruses has been going on for a long time, in and outside the forested area, in at least nine districts of the region. Men, and especially fishermen, among other professions, who generally work in the evening and at night, present the highest risk of infection.

UNITERMS: Hemagglutination inhibition tests. Arboviruses Serological surveys.

\section{REFERENCIAS BIBLIOGRAFICAS}

1. BERGE, T.O., ed. International catalogne of arboviruses. 2nd ed. Washington, D.C. US Dept. Health, 1975. (Publ. 75-8301).

2. BUCKLEY, S.M. \& SHOPE, R.E. Comparative assay of arthropod-borne group $\mathrm{C}$ rirus antibodies by tissue culture neutralization and hemagglutination-inhibition tests. Amer, J. trop. Med. Hyg. $10: 53-61.1961$.

3. CALISHER, C.H. et al. Isolations of new Alpha and Bunyaviruses of Southern Brazil: proposed reclassification of serogroups [Trabalho apresentado ao Simpósio Internacional de Febres Hemorrágicas e Arbovírus dos Trópicos. Belém 1980]

4. CAMARGO, J.C.G. et al. Estudo fitogeográfico e ecológico da bacia hidrográfica paulista do Rio Ribeira. São Paulo, Instituto de Geografia da USP. 1972. (Série Biogeografia. 5).

5. CASALS, J. Immunological techniques for animal viruses. In: Maramorosh. K. \& Koprowski, H. Methods in virology. New York, Academic Press, 1967. ․ 3. p. $175-81$.
6. CASALS, J. Immunological relationships among central nervous system viruses. J. exp. Med., 79:341-59, 1944

7. CASALS, J. Relationships among arthopod-borne animal viruses determined by cross-challenge tests. Amer, J. trop. Med. Hyg., 12:587-96, 1963.

8. CASALS, J. \& WHITMAN, L. Group C. a new serological group of hitherto undescribed arthropod-borne viruses, immunological studies. Amer. J. trop. Med. Hyg., $\quad 10: 250-8,1961$.

9. CAUSEY, O.R. et al. Arthropod-borne rirus in Brazil. Amer. J. trop. Med. Hygl. $10: 227-49$, 1961.

10. FORATTINI, O.P. et al. Estudos ecológicos sobre mosquitos Culicidae no sistema Serra do Mar. Brasil. 1 - Observações no ambiente extradomiciliar. Rer. Suúde públ., S. Paulo, 12:297-325, 1978.

11. FORATTINI. O.P. et al. Estudos ecológicos sobre mosquitos Culicidae no sistema da Serra do Mar. Brasil. 2 - Observações no ambiente domiciliar. Rev. Saude públ. S. Paulo, 12:476-96. 1978 
IVERSSON, L. B. et al. Estudos sorológicos para pesquisa de anticorpos de arbovirus em população humana da regiăo do Vale do Ribeira. II - Inquérito em pacientes do Hospital Regional de Paquera-Açú, 1980. Rev. Saúde públ., S. Paulo, 15:587-602, 1981.

12. IVERSSON, L.B. Aspectos da epidemia de encefalite por arbovírus na região do Vale do Ribeira, São Paulo, Brasil, no periodo de 1975 a 1978. Rev. Saúde públ., S. Paulo, 14:9-35,1980.

13. IVERSSON, L.B. Epidemia de encefalite por arbovírus na região Sul do Estado de São Paulo, Brasil, em 1975 e 1976. aspectos da distribuição cronológica $\epsilon$ geográfica dos casos. Rev. Saúde públ., S. Paulo, $11: 375-88,1977$.

14. IVERSSON, L.B. et al. Estudos sorologicos para pesquisa de anticorpos de arbovirus na população h:mana da região do Vale do Ribeira. I - Seguimento sorológico de grupo populacional residente em ambiente silvestre. [Trabalho apresentado ao Simpósio Internacional de Febres Hemorrágicas e Arbovirus dos Trópicos, Belém, 1980].

15. LOPES, O. de $S$. Rocio (ROC) strain: SPH 34675. Amer. J. trop. Med. Hyg., $27: 418-9,1978$.

16. LOPES, $O$. de $S$. et al. Emergence of a new arbovirus disease in Brazil. I Isolation and characterization of the etiologic agent, Rocio virus. Amer. J. Epidem., 107:444-9, 1978.

17. LOPES, O. de $\mathrm{S}$. et al. Emergence of a new arbovirus disease in Brazil. II Epidemiologic studies on 1975 epidemic. Amer, J. Epidem., 108:394-401, 1978.

18. LOPES, $\mathrm{O}$, de $\mathrm{S}$. et al. Isolation of $\mathrm{St}$. Louis encephalitis virus in So:th Brazil. Amer. J. trop. Med. Hyg., 28:583-5, 1979.

19. SECRETARIA DE ECONOMIA E PLANE. JAMENTO. Conhesa seu municipio. regiāo do Vale do Ribeira. São Paulo. 1974. v. 1 .
20. SETZER, J, Atlas climático e ecológico do Estado de São Paulo. São Palilo, Comissão Interestadual da Bacia Paraná-Urugual e Centrais Elétricas de São Paulo, 1966.

21. SHOPE, R.E. The use of micro-hemagglu. tination - inhibition test to follow antibody response after arthropod-borne virus infection in a community of forest animals. An. Microbiol., 11:167-71, 1963.

22. SHOPE, R.E. \& CAUSEY, O.R. Further studies on the serological relationship of Group $C$ arthropod-borne viruses and the application of these relationships do rapid identification of types. Amer. $J$. trop. Med. Hyg., 11:283-90, 1962.

23. SUDELPA. Area de atuação; caracterização físico-econômico-social. São Paulo, Secretaria de Economia e Planejamento. 1974. v. 1 .

24. THEILER, M. \& CASALS, J. The serological reactions in yellow fever. Amer. J. trop. Med. Hyg., 7:585-94, 1958.

25. TIRIBA, A. de C. Epidemia de encefalite atribuida a arbovirus ocorrida no litoral Sul do Estado de São Paulo, em 1975, contribuição para o estudo clinico. São Paulo, 1975. i'Tese de Livre Docência. - Escola Paulista de Medicina]

26. TIRIBA, A. de $\boldsymbol{C}$. et al. Encefalite humana primária epidèmica por arbovírus observada no litoral Sul do Estauo de São Paulo. Rev. Ass. méd. bras., 22:415-20, 1976 .

Receoido para publicąāo em 15/07/1981

Aprovado para publicacão em 17/11/1981 